\title{
Enhancement of Bleomycin Sensitivity in Human Lung Cancer Cell Line using Centella asiatica Leaf Extract
}

\author{
Yang $\mathrm{Wu}^{1 *}$, Shi Gao ${ }^{1}$ and Tan Yuan ${ }^{2 *}$ \\ ${ }^{1}$ Department of Surgery, the First Affiliated Hospital of Zhengzhou University, Zhengzhou 450052, China; ${ }^{2}$ Department of \\ Respiratory Diseases, The Fifth Affiliated Hospital of Zhengzhou University, Zhengzhou 450052, China \\ *For correspondence: Email: dryuantan@hotmail.com; drwuyang@126.com; Tel/Fax:0086-371-66916919; 0086-371- \\ 67967122

\begin{abstract}
Purpose: To demonstrate the effectiveness of Centella asiatica aqueous extract in augmenting the cytotoxic effect of bleomycin in the adenocarcinoma human alveolar basal epithelial A549 cell line.

Methods: The inhibitory effect of bleomycin on A549 cells was determined by incubating the cells for 24 $h$ in different concentrations of bleomycin. The effect of C. asiatica extract on A549 cells was determined after exposing cells to 5, 10,15, 20, 25, and $30 \%(\mathrm{v} / \mathrm{v})$ bleomycin diluted from an initial 10\% stock solution. Based on the $50 \%$ inhibitory $\left(I C_{50}\right)$ values of bleomycin, 80, 100, and $120 \mu \mathrm{g} / \mathrm{mL}$ concentrations were tested with 15,20 , and $25 \%(\mathrm{~V} / \mathrm{V})$ of $C$. asiatica extract.

Results: $I C_{50}$ value of bleomycin on A549 cells was $100 \mu \mathrm{g} / \mathrm{mL}$, and was reduced to $80 \mu \mathrm{g} / \mathrm{mL}$ when cells were co-incubated with $20 \% \mathrm{~V} / \mathrm{v}$ of $\mathrm{C}$. asiatica extract. The results show that $\mathrm{C}$. asiatica extract reduces the concentration of bleomycin necessary for inhibition of $A 459$ cell growth $\left(I C_{50}\right)$. While the $I_{50}$ value of bleomycin was $100 \mu \mathrm{g} / \mathrm{ml}$, it fell to $80 \mu \mathrm{g} / \mathrm{m} /$ when used along with $20 \% \mathrm{v} / \mathrm{v}$ CA extract ( $p<$ 5)

Conclusions: This study demonstrates that compounds extracted from C. asiatica may have potential for use as adjuvants in bleomycin cancer chemotherapy.
\end{abstract}

Keywords: Centella asiatica, A549 cells, Bleomycin, Lung cancer, Increased susceptibility, Cell viability

Tropical Journal of Pharmaceutical Research is indexed by Science Citation Index (SciSearch), Scopus, International Pharmaceutical Abstract, Chemical Abstracts, Embase, Index Copernicus, EBSCO, African Index Medicus, JournalSeek, Journal Citation Reports/Science Edition, Directory of Open Access Journals (DOAJ), African Journal Online, Bioline International, Open-J-Gate and Pharmacy Abstracts

\section{INTRODUCTION}

Phytochemicals are plant products used in traditional medicine. Several currently used therapeutic drugs are based on phytochemicals. Although plant products have been used for several centuries, the exact mechanisms by which these compounds function remain unknown, and further evidence-based dose effects of the phytochemicals are required.

Centella asiatica is a herb of Asian origin belonging to the Apiaceae family and the Mackinlayoideae subfamily, also commonly known as the "gotu kola" or "centella." Grown in wet areas; the leaves of this herb are commonly used in a variety of ways, ranging from preparing juices to porridges and salads. The medicinal uses of $C$. asiatica are well documented in a review by Kashmira et al [1]. Plant extracts of $C$. asiatica have been widely used to treat skin diseases, varicose veins, to reduce hypertension, to improve memory, and for wound healing. Its major use is as a brain tonic for improving nervous function [1].

The extracts from the leaves and tender stems of C. asiatica confer beneficial effects from 
compounds including triterpenoids, saponins, sapogenins, brahmoside, brahminoside, isothankuniside, thankuniside, sterols, flavanoids, indocentelloside, asiaticoside, and tannins. The two most active ingredients are bacoside $A$ and bacoside $B$. Apart from their wound healing properties the triterpenoid compounds from $C$. asiatica exert beneficial effects primarily on the circulatory and the nervous systems. A comprehensive study of the herb, its natural compounds, the beneficial health effects, and pharmacological aspects of $C$. asiatica are available online from Examine.com, a portal that provides detailed evidence-based, scientific information on food supplements [2].

Cancers are a major global human health care concern with the types and incidence levels increasing at a significant rate. Cancers are complex diseases making them a challenge to understand, manage, and treat. This makes it very important to treat cancer using combinations of approaches. Targeted therapy, gene therapy, and rendering cancer cells more susceptible to therapeutic drugs are currently in use. While the discovery of new drugs is critical, enhancing the effects of currently available chemotherapeutic drugs can also be useful. Modulators that enhance the effectiveness of radiotherapy and chemotherapy can be used as adjuvants and offer several advantages [3].

In this regard, the use of pulsed electromagnetic field treatments includes studies with radiotherapy [4] as well as with chemotherapeutic drugs [5]. Other well-studied modulators for cancer therapy include antibodies used as immunostimulatory agents [6], metal compounds such as arsenic trioxide [7], statins such as simvastatin [8], isoflavones from soy [9], prostaglandin inhibitors [10], and nanoparticles [11].

Established and well-characterized cancer cell lines are widely used for cancer research. There are many cancer cell lines currently available for research purposes. These continuous cell lines offer unique advantages as model systems. A549 is an adenocarcinoma human alveolar basal epithelial cell line. Bleomycin is a widely used cancer chemotherapeutic drug and several in vitro studies have shown the usefulness of bleomycin (a radiomimetic drug) on cancer cell lines used as models for cancer research. The effects of bleomycin on lung epithelial cells are well-known [12-14]. Bleomycin was also used to study the modulatory effects of caveolin-1 on apoptosis and senescence in lung cells, making this model a reliable choice to determine the modulatory or synergistic effects of supplements [15].

We determined the possible augmentative effects of $C$. asiatica leaf extract on the anticancer cytotoxic effects of bleomycin in A549 cells. The role of $C$. asiatica in radioprotection of A549 cells has been previously studied. An active ingredient of $C$. asiatica, asiatic acid, was shown to have inhibitory effects on A549 cell growth [16]. The documented applications of $C$. asiatica in radioprotection or during radiotherapy also include advantageous psychological effects such as positive behavioural changes [17]. C. asiatica extracts were also shown to be advantageous (at $100 \mathrm{mg} / \mathrm{kg}$ body weight) in increasing the survival and minimizing body weight loss in Swiss albino mice exposed to Cobalt-60 (60Co) gamma radiation at a sublethal dose of 8 Gy [18].

In this study, we assessed the potential use of $C$. asiatica for cancer therapy as a supplement or as an adjunctive agent. Treatments which increase the sensitivity of cancer cells to a therapeutic drug can result in a decreasing dose, thereby avoiding some of the side effects of such drugs on normal cells and tissues. Further studies should determine the usefulness of commonly available phytochemicals as augmentative cancer therapeutics.

\section{EXPERIMENTAL}

C. asiatica were collected from a natural habitat with no apparent pollution and the stems along with the leaves were harvested, cleaned three times with sterile distilled water, and then with phosphate-buffered saline (PBS). The leaves and tender stems were dried in an oven for $84 \mathrm{~h}$ at $45{ }^{\circ} \mathrm{C}$ and were then milled to obtain a powder. The aqueous extract was obtained from this powder by adding $100 \mathrm{~mL}$ of distilled water to every $10 \mathrm{~g}$ of the plant powder to obtain a 10 $\% \mathrm{w} / \mathrm{v}$ concentration of the final extract. The mixture was incubated at $4{ }^{\circ} \mathrm{C}$ for $1 \mathrm{~h}$, refluxed, vacuum filtered, and then sterilized using 0.4 micron filters followed by a 0.2 micron filter. Ten grams of the plant powder was extracted using $100 \mathrm{~mL}$ of distilled water to obtain a final concentration of $10 \% \mathrm{v} / \mathrm{v}$. Aliquots of the extract (CA extract) were stored at $4{ }^{\circ} \mathrm{C}$ and various concentrations were obtained using the $10 \%$ stock solution.

The A549 cells obtained from American Type Culture Collection (ATCC), USA were maintained in Dulbecco's Minimum Essential Medium 
(DMEM) obtained from Gibco BRL, USA supplemented with $10 \%$ fetal bovine serum in T24 flasks, and were passaged when they reached $90 \%$ confluency. The A549 cells were cultured in 12-well plates to determine the $\mathrm{IC}_{50}$ values of bleomycin and the effects of CA extracts. Triplicate cultures in 12-well plates were used for each concentration of bleomycin, CA extract, and the combinations of bleomycin and $\mathrm{CA}$ extract. The seeding density for all experiments was $0.16 \times 10^{6}$ cells per well and cells were > $97 \%$ viable, and at $50 \%$ confluency.

The doses used to determine the $I_{50}$ value of bleomycin-induced cytotoxicity on A549 cells were $20,40,60,80,100,120,140,160,180$, and $200 \mu \mathrm{g} / \mathrm{mL}$. Cells were incubated for $24 \mathrm{~h}$, the monolayers were washed three times with sterile PBS, trypsinized, and cell viability was calculated using trypan blue dye exclusion.

The doses of the CA extract used to study its effects on the A549 cells were $5,10,15,20,25$, and $30 \%(\mathrm{v} / \mathrm{v})$ from the stock $10 \%$ solution. Cells were incubated for $24 \mathrm{~h}$ with the CA extract and the viability was calculated. Based on the $I_{50}$ values of bleomycin and the effects of $C A$ extracts on the A549 cells, bleomycin was used at 80,100 , and $120 \mu \mathrm{g} / \mathrm{mL}$, and each of these concentrations were tested with 15,20 , and $25 \%$ $(\mathrm{v} / \mathrm{v})$ of CA extract, in triplicate to ascertain the modulatory effects of $\mathrm{CA}$ extract on bleomycin inhibitory activity. Cells were incubated in the bleomycin-CA extract combinations for $24 \mathrm{~h}$ and viability calculated as described.

\section{Statistical analyses}

The percent cytotoxicity at various levels of bleomycin was determined, and the $\mathrm{IC}_{50}$ was determined as the concentration of the drug which induced killing of $50 \%$ of the cell population. Samples were in triplicate and results are expressed as mean \pm SD. Statistical analysis included the percent cytotoxicity and the maximum percent toxicity. The association of the cytotoxic drug individually and in combination with the phytochemical extract was shown by graphs using Excel software.

\section{RESULTS}

In total, $100 \mathrm{~mL}$ of the $\mathrm{CA}$ aqueous extract was obtained and was stored as aliquots at $4{ }^{\circ} \mathrm{C}$. There was a dose-dependent increase on the cytotoxic effect of bleomycin on A549 cells with an $\mathrm{IC}_{50}$ value of approximately $100 \mu \mathrm{g} / \mathrm{mL}$ (Figure 1).

Of the six concentrations of the CA leaf extract used, the 5, 10, 15, and $20 \%(\mathrm{v} / \mathrm{v})$ concentrations did not have any effects on the A549 cells. However, the cells exposed to $25 \%$ and $30 \% \quad(\mathrm{v} / \mathrm{v}) \quad \mathrm{CA}$ extract showed cell granulation and debris in the culture medium (Figure 2).

The optimal concentration of CA extract was 20 $\% \quad(\mathrm{v} / \mathrm{v})$ for bleomycin $\mathrm{IC}_{50}$ of $80 \mu \mathrm{g} / \mathrm{mL}$. Combinations of bleomycin with 15 and $25 \%$ $(\mathrm{v} / \mathrm{v})$ CA extracts did not provide enhancement when compared to cells exposed to 100 or 120 $\mu \mathrm{g} / \mathrm{mL}$ bleomycin alone. In summary, supplementation with $20 \%$ (v/v) CA extract provided significant enhancement of bleomycin sensitivity for A549 cells.

\section{DISCUSSION}

C. asiatica is well documented in the scientific literature for its beneficial human healthcare effects. Although its applications for various indications such as neurological disorders, vascular disorders, and wound healing are well documented, it was of interest to determine if it has synergistic action on commonly used therapeutic drugs. Bleomycin is a radiomimetic cancer chemotherapeutic drug widely used with cell cultures in vitro to study therapeutics.

A549 cells exposed to bleomycin for $24 \mathrm{~h}$ exhibited an $\mathrm{IC}_{50}$ of $100 \mu \mathrm{g} / \mathrm{mL}$. Exposure to CA extracts did not have apparent effects, although the cells had aberrant morphology when supplemented with $25 \%$ and $30 \%(\mathrm{v} / \mathrm{v}) \mathrm{CA}$. This might be due to the changes in the medium characteristics and composition when supplemented with the additional volumes from the given extract. Three concentrations of bleomycin were used for combination experiments based on the $\mathrm{IC}_{50}$ value of bleomycin on the A549 cells. In addition, three concentrations of the CA extract that did not cause aberrant cell morphology were used for the combination exposure studies. While $15 \%$ and $25 \%(\mathrm{v} / \mathrm{v})$ of $\mathrm{CA}$ extract did not show modulatory effects alone, the $20 \%(\mathrm{v} / \mathrm{v}) \mathrm{CA}$ enhanced the inhibitory effect of bleomycin on the $A 549$ cells. The $\mathrm{IC}_{50}$ of $100 \mu \mathrm{g} / \mathrm{mL}$ bleomycin alone was reduced to $80 \mu \mathrm{g} / \mathrm{mL}$ when cells were supplemented with $20 \%$ (v/v) CA extract. In. 


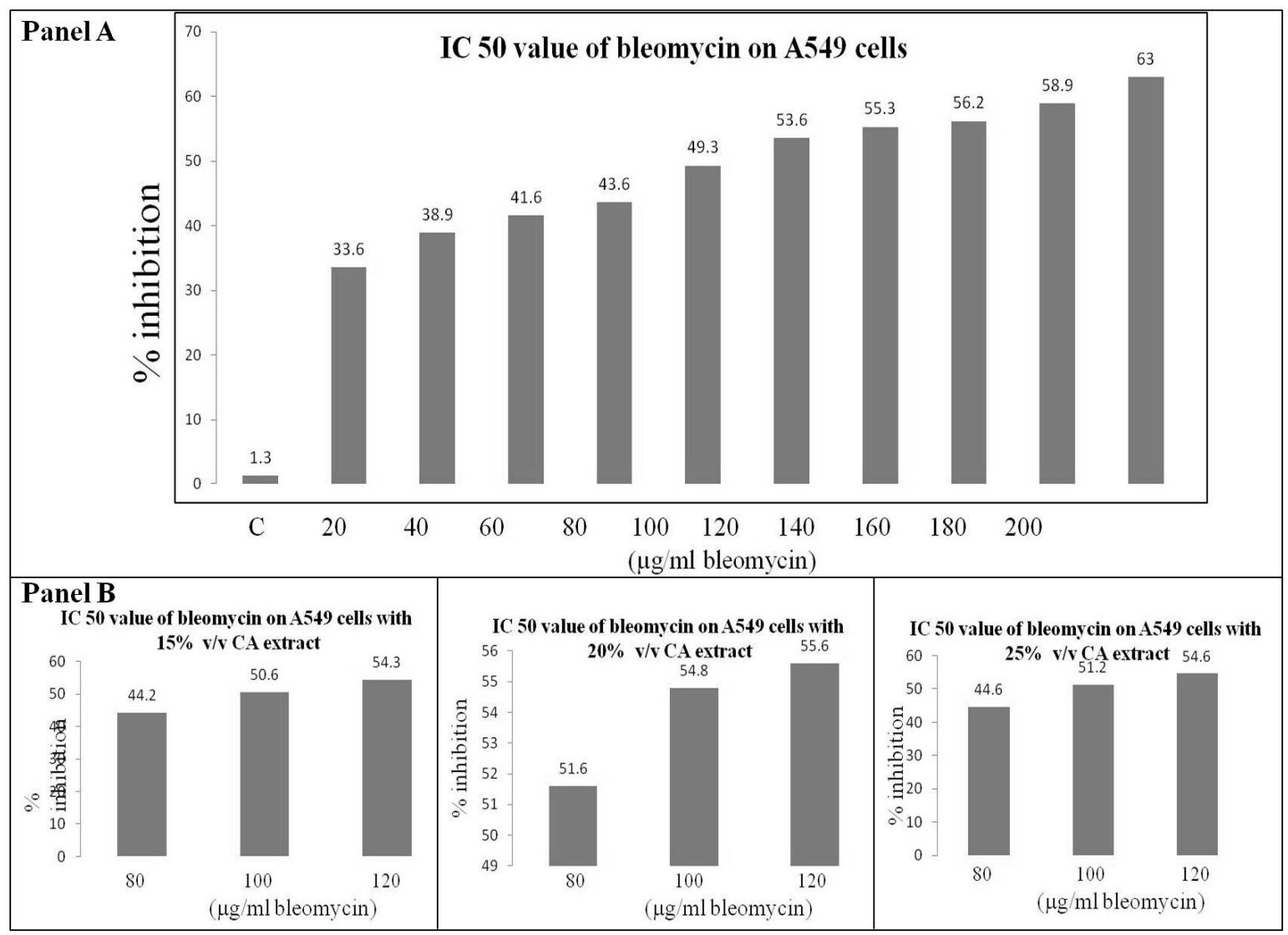

Figure 1: Panel A. Bleomycin induced dose-dependent cytotoxicity on A549 cells when given for $24 \mathrm{~h}$. The IC 50 value of bleomycin was $100 \mu \mathrm{g} / \mathrm{mL}$. Panel B. A549 cells incubated with 80, 100, and $120 \mu \mathrm{g} / \mathrm{mL}$ bleomycin combined with 15, 20, and $25 \%(\mathrm{v} / \mathrm{v})$ CA extract demonstrated that the combination of $80 \mu \mathrm{g} / \mathrm{mL}$ bleomycin and $20 \%(\mathrm{v} / \mathrm{v})$ CA extract gave a synergistic enhancement of the inhibitory effects of bleomycin. This combination resulted in a reduction of the $\mathrm{IC}_{50}$ value of bleomycin to $80 \mu \mathrm{g} / \mathrm{mL}$, compared to $100 \mu \mathrm{g} / \mathrm{mL}$ with bleomycin alone. However, there was no significant change in the $\mathrm{IC}_{50}$ values in cultures with a combination with either $15 \%$ or 25 $\%(v / v)$ CA extract

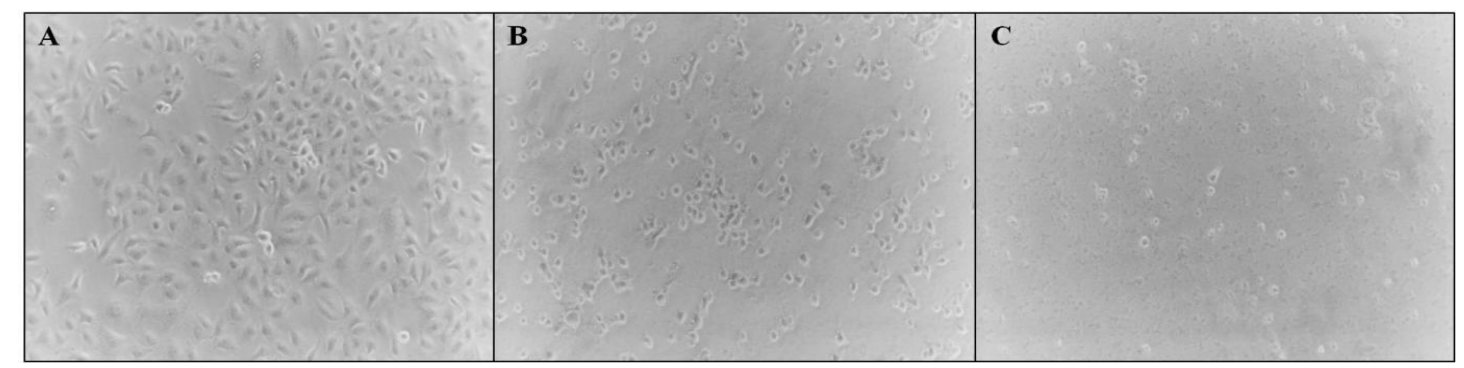

Figure 2: (A) A549 cells exposed to 5, 10, 15, and $20 \%(\mathrm{v} / \mathrm{v})$ from the $10 \%$ initial stock solution of CA extract did not exhibit any morphological changes; however, the cultures exposed to $25 \%$ and $30 \%$ (v/v) CA extract from the initial $10 \%$ stock solution of CA extract did show morphological changes (B) and (C), perhaps due to increased culture volumes from the CA extracts. Cell morphology was markedly altered as seen in panel 3 with less adhered spindle-shaped healthy cells. Also, granulation and debri were seen to increase in cultures supplemented with $30 \%(v / v)$ CA extract

summary, our study demonstrates synergistic and modulatory effects of CA extract, and suggests the importance of choosing the correct combination doses for maximizing the effectiveness of chemotherapeutic drugs

\section{CONCLUSION}

Phytochemicals have been in use in human health care for several centuries. However, additional data are required for their acceptance and wide utilization. $C$. asiatica is well 
documented for its human health care applications and its mechanisms of action have been studied. The findings of this study indicate the usefulness of $C$. asiatica as an adjuvant for augmenting bleomycin in lung cancer therapy.

\section{ACKNOWLEDGEMENT}

This work was supported by the Henan Province Science Foundation of China (Grant No.14A320070). The authors thank the management of the Departments and Hospitals of affiliation for the support.

\section{REFERENCES}

1. Gohil KJ, Patel JA, Gajjar AK.. Pharmacological Review on Centella asiatica: A potential herbal cure-all. Indian J Pharm Sci 2010; 72(5): 546-556.

2. All essential benefits/effects/facts \& information [cited 2015 July 11]. Available from http://examine.com/supplements/Centella+asiatica/

3. Danhier P, De Saedeleer CJ, Karroum O, De Preter G, Porporato $P E$, Jordan $B F$, Gallez $B$, Sonveaux $P$. Optimization of tumor radiotherapy with modulators of cell metabolism: toward clinical applications. Semin Radiat Oncol 2013; 23(4): 262-272.

4. Omote $Y$, Hosokawa $M$, Komatsumoto $M$, Namieno $T$, Nakajima S, Kubo $Y$, Kobayashi $H$. Treatment of experimental tumors with a combination of a pulsing magnetic field and an antitumor drug. Jpn J Cancer Res 1990; 81(9): 956-961.

5. Ruiz-Go'mez MJ, Marti'nez-Morillo M. Enhancement of the cell-killing effect of ultraviolet- $C$ radiation by shortterm exposure to a pulsed magnetic field. Int $\mathrm{J}$ Radiat Biol 2005; 81: 483-490.

6. Inge V, Mara G, Mark JS, Ricky WJ, Nicole MH. Enhancing the antitumor effects of radiotherapy with combinations of immunostimulatory antibodies. Oncoimmunol 2012; 1(9): 1629-1631.

7. Lin YC, Li DR, Lin W. Relationship between radiotherapy enhancing effect of arsenic trioxide and the proliferation and apoptosis of related protein in nasopharyngeal carcinoma patients. Zhongguo Zhong Xi Yi Jie He Za Zhi 2007; 27(8): 704-707.

8. Lara I. de Llobet, Marta B, Ricard M, Josep $B$. Simvastatin enhances the effects of radiotherapy and cetuximab on a cell Line ( $F a D u)$ derived from a squamous cell carcinoma of head and neck. Transl Oncol 2014; 7(4): 513-522.

9. Gilda GH, Vinita SG, David JH, Lisa A, Joseph $R$, Christopher KY, Shoshana ER, Fazlul HS, Shirish G, Andre AK, Fulvio L, Michael CJ. Differential effect of soy isoflavones in enhancing high intensity radiotherapy and protecting lung tissue in a pre-clinical model of lung carcinoma. Rad Therapy Oncol 2013; 109(1): 117-125.

10. Hak C, Luka M. enhancing radiotherapy with cyclooxygenase-2 enzyme inhibitors: A rational advance? Natl Cancer Inst 2003; 95(19): 1440-1452.

11. James FH, Avraham FD, Daniel NS, Henry MS. Radiotherapy enhancement with gold nanoparticles. JPP 2008; 60: 977-985.

12. Sato E, Koyama S, Masubuchi T, Takamizawa A, Kubo $K$, Nagai S, Izumi T. Bleomycin stimulates lung epithelial cells to release neutrophil and monocyte chemotactic activities. Am J Physiol 1999; 276(6): L941-L950.

13. AoshibaK, TsujiT, NagaiA Bleomycin induces cellular senescence in alveolar epithelial cells. Euro Resp $J$ 2003; 22(3): 436-443.

14. Annett L, Nobuhiro M, Michael K, Kathrin B. Bleomycin induces caveolin-1 and -2 expression in epithelial lung cancer A549 Cells. Anticanc Res 2007; 27: 1343-1352.

15. Michael K, Kathrin B. Bleomycin and its role in inducing apoptosis and senescence in lung cells - modulating effects of caveolin-1. Current Cancer Drug Targets 2009; 9: 341-353.

16. Wang L, Xu J, Zhao C, Zhao L, Feng B. Antiproliferative, cell-cycle dysregulation effects of novel asiatic acid derivatives on human non-small cell lung cancer cells. Chem Pharm Bull (Tokyo) 2013; 61(10): 1015-1023.

17. Shobi V, Goel HC. Protection against radiation-induced conditioned taste aversion by Centella asiatica. Physiol Behav 2001; 73: 19-23.

18. Sharma J, Sharma R. Radioprotection of Swiss albino mouse by Centella asiatica extract. Phytother Res 2002; 16: 785-786. 